\title{
Recurrent respiratory papillomatosis: an overview of current thinking and treatment
}

\author{
Peter Goon · Chris Sonnex • Piyush Jani • \\ Margaret Stanley $\cdot$ Holger Sudhoff
}

Received: 3 March 2007 / Accepted: 16 November 2007 / Published online: 29 November 2007

(C) Springer-Verlag 2007

\begin{abstract}
Human papillomaviruses (HPV) infection in benign laryngeal papillomas is well established. The vast majority of recurrent respiratory papillomatosis lesions are due to HPV types 6 and 11. Human papillomaviruses are small non-enveloped viruses ( $>8 \mathrm{~kb}$ ), that replicate within the nuclei of infected host cells. Infected host basal cell keratinocytes and papillomas arise from the disordered proliferation of these differentiating keratinocytes. Surgical debulking of papillomas is currently the treatment of choice; newer surgical approaches utilizing microdebriders are replacing laser ablation. Surgery aims to secure an adequate airway and improve and maintain an acceptable quality of voice. Adjuvant treatments currently used include cidofovir, indole-3-carbinol, ribavirin, mumps vaccine, and photodynamic therapy. The recent licensing of prophylactic HPV vaccines is a most interesting development. The low incidence of RRP does pose significant problems in recruitment of sufficient numbers to show statistical significance. Large multi-centre collaborative clinical trials are therefore required. Even so, sufficient clinical follow-up data would take several years.
\end{abstract}

Keywords Recurrent respiratory papillomatosis . Human papilloma virus · HPV 6 and $11 \cdot$ Vaccination

P. Goon · C. Sonnex

Department of Genito-urinary Medicine,

Addenbrooke's Hospital, Cambridge, UK

P. Goon · M. Stanley

Department of Pathology, University of Cambridge,

Cambridge, UK

P. Jani $\cdot$ H. Sudhoff $(\square)$

Department of Otolaryngology and Skull Base Surgery,

Addenbrooke's Hospital, Cambridge, UK

e-mail: holger.sudhoff@rub.de

\section{Introduction}

Sir Morrell Mackenzie (1837-1892) was the first to recognize papillomas as a lesion of the laryngo-pharyngeal system in children in the late 1800s. It is now apparent that these benign tumours may occur at other parts of the upper gastrointestinal and respiratory tracts, and in all age groups. It was not until the 1940s that Chevalier Jackson (18651958) first coined the term "juvenile laryngeal papillomatosis". The prevalence of laryngeal papillomatosis has been estimated at between four to seven cases per million person-years in the Western World [4, 5, 25, 43]. Furthermore, the incidence of recurrent respiratory papillomatosis (RRP) has been estimated at about 2 per 100,000 in adults and 4 per 100,000 in children [9]. The disease can be categorized into adult onset and juvenile onset forms. Age of first presentation of disease is usually in the teens $(50 \%)$ for the juvenile onset form but can be as early as the first year of life. Initial presentation in the adult form tends to peak in the third and fourth decades.

It is now well established that human papillomaviruses (HPVs) are the aetiological agent of many benign and malignant tumours arising from epidermal tissues. They are a necessary cause of the second most common female cancer worldwide, cancer of the cervix [7, 45], and strongly associated with several other ano-genital cancers such anal, penile, vulval and vaginal carcinomas [17]. Furthermore, there is mounting evidence of at least some head and neck cancers associated with HPV infection [15, 17, 23]. These malignancies are associated with $\sim 15$ high risk (HR) types, in particular HPV 16, 18, 31, 33, 35, 39, 45, $51,52,56,58,59,68,73$ and 82 . Benign tumours such as common warts, flat warts and genital warts are caused by low risk types such as HPV 1, 2, 3, 4, 6, 10, 11 and others. HPV 6 and 11 have been described as the dominant types 
found in RRP [10]. Despite the benign nature of these lesions, there is significant morbidity and occasional mortality due to multiple recurrences which necessitate hospital admission for surgical removal. Dissemination or extension of the growths into the lower airways indicates a poorer prognosis. The clinical behaviour is variable and lesions can regress, persist and in rare instances, progress to carcinoma if other environmental factors such as smoking or irradiation are involved.

\section{Epidemiology}

Human papillomaviruses infection in benign laryngeal papillomas is well established. One Danish study showed that 95\% of solitary laryngeal papillomas were positive for HPV DNA by in situ hybridization [26]. Another study from Hong Kong found that $59 \%$ of laryngeal papillomas showed the presence of HPV 6, 11, 16, 18 subtypes, with 6 and 11 the dominant types [10]. Malignant transformation of some lesions has been described in association with HPV 11 integration into the genome and mutation of p53 [32]. Infection with HPV 11 is more likely to be associated with the development of distal airways disease than HPV 6 . Clinical manifestation of disease prior to three years of age is a further risk factor associated with distal spread of disease $[1,47]$.

The vast majority of RRP lesions are due to HPV types 6 and 11, and the reservoir for these types is the human anogenital tract. Ano-genital HPV is the commonest sexually transmitted viral infection and the prevalence of clinically apparent genital warts is thought to be the "tip of the iceberg" of HPV infection. Koutsky et al. estimates that $\sim 10$ $20 \%$ of the US population between 15 and 49 years of age have molecular evidence of infection and that another $60 \%$ have had prior infection [22]. In the UK, there were well over 81,000 incident genital wart infections reported from genitourinary medicine clinics in 2005 [16] and this has been increasing every year. Such high background prevalence suggests that there is a risk of mother to child transmission at the time of delivery, especially if there are noticeable genital warts. Data supporting this hypothesis showed that a history of maternal condylomata during pregnancy was associated with a 200-fold risk of RRP in the child [37]. An uncomplicated vaginal delivery in a mother with HPV infection has been estimated to carry a risk of transmission of 1:80-1:1,500 (median of 1:400) [34]. In one group of children with juvenile laryngeal papillomatosis, $54 \%$ had a maternal history of vulval condylomata at the time of delivery [13]. Another study found that in 77 mothers with condylomata at delivery, 9 children (11.6\%) were later diagnosed with juvenile laryngeal papillomatosis [21].
The route of transmission is likely to be different in the juvenile onset and adult onset forms of RRP. Evidence for this has been suggested by a case control study, in which the risk factors for both forms were compared [20]. The authors found that adult onset patients were more likely to have had more sexual partners and oral sex than their controls. Patients with the juvenile form were more likely to have been born to teenage mothers and first-born children compared to their controls.

\section{Aetiological and histopathological features}

Papillomatous lesions preferentially occur anatomically at the sites of "transformation zones", where squamous epithelia abut ciliated columnar epithelia but can infect anywhere in the respiratory tract [28]. The classical sites for recurrent disease in the upper aero-digestive tract would be the nasopharyngeal area of the soft palate, limen vestibuli, midzone of laryngeal area of the epiglottis, upper and lower margins of the ventricle, vocal fold undersurface, carina and bronchial spurs. It is interesting to note that papillomata have been observed at tracheotomy sites and tracts where the iatrogenic induction of change of epithelialization also occurs [19].

Human papillomaviruses are small nonenveloped viruses $(\sim 8 \mathrm{~kb})$, with a double stranded circular DNA genome encapsulated within an icosahedral capsid that replicate within the nuclei of infected host cells. The genome codes for $8-10$ genes (median of eight). The late L1 and L2 genes code for the viral capsid proteins, the early proteins $\mathrm{E} 1$ and E2 are responsible for viral replication and transcription, and E4 appears to aid virus release from infected cells. The early genes E6 and E7 have transforming ability in in vitro assays for HR types but LR types have little to no ability for this feature [2, 33, 42].

Electron microscopic analysis reveals the virion to be $\sim 55 \mathrm{~nm}$ in diameter and the capsid to be comprised of 72 pentameric capsomers. The predominant protein in the capsid consists of the L1 protein, with a smaller proportion of L2 embedded deep within the protein shell. It is this L1 protein which provides the dominant antigenic epitopes recognized by neutralizing antibodies and forms the basis for the bivalent (GlaxoSmithKline) and quadrivalent (Merck, Hohenbrumn, Germany) vaccines currently available.

The virus is thought to bind to and gain entry to its host cell, the basal keratinocyte, by microtrauma or abrasions to the surface epithelium. The receptor has not been definitively identified but $\alpha 6$-integrin and heparin sulphate may play important roles in viral entry $[11,18,30]$.

Following infection and uncoating, the virus is thought to maintain its genome as a low copy number episome in 
the basal cells. It has been suggested that expression of E1 and possibly E2, may be sufficient for basal maintenance of viral episomes [50]. Viral early proteins E6, E7, E1 and E2 are expressed at low level in early passage cell lines derived from naturally occurring low-grade cervical lesions and the viral genome is maintained at around $10-200$ copies per cell $[8,41]$.

The viral genome is amplified in differentiating keratinocytes via rolling-circle amplification that will synthesize sufficient viral genome for packaging [3, 12]. This requirement for differentiating epithelial cells is a key part of the virus life cycle but the normal restraint on cell cycle progression appears to be abolished by the E6 and E7 proteins and normal terminal differentiation is retarded [36]. These E6 and E7 effects on key apoptotic proteins such as Rb and p53 have been demonstrated in HPV 16 and other high-risk subtypes in in vitro assays [24, 27, 28]. HPV 6 and 11 E6 and E7 proteins do not readily bind to or degrade the p53 or $\mathrm{Rb}$ proteins $[14,31,46]$. This suggests that alternative mechanisms of altered cellular growth and proliferation may exist for the low-risk subtypes of HPV. Furthermore, there are little data on HPV 6 and 11 life cycles, replication, maintenance and viral production in respiratory cells. It is not known if these are similar to or different to disease in the ano-genital region.

\section{Treatment}

\section{Surgical}

Surgical debulking is currently the treatment of choice; newer surgical approaches utilizing microdebriders are replacing laser ablation. Surgical excision aims to secure an adequate airway and improve and maintain an acceptable quality of voice [49].

HPV is present in the normal macroscopically unaffected mucosa and it is currently not possible to distinguish infected cells with a normal appearance from uninfected epithelia. Repeated recurrences are frequent, however, repeated attempts to treat the papillomas may cause serious complications [40]. Current practice in the treatment of RRP was recently evaluated by a questionnaire in the UK [44]. Various lasers such as $\mathrm{CO}_{2}, \mathrm{KTP}$, and pulsed dye were found to be the preferred method of surgical removal of RRP in children [49]. Spontaneous ventilation (65.3\%) is the preferred method of anaesthesia.

The frequent recurrence of papillomas has resulted in the use of different adjuvant treatments alongside surgical removal of macroscopically obvious in the attempt to improve outcomes. In the future, advances in the understanding of the immune response to HPV may improve our treatment modalities and prevention strategies.
Adjuvant treatment

Adjuvant treatments currently used include cidofovir, indole-3-carbinol, ribavirin, mumps vaccine, and photodynamic therapy. As with surgical management, viral persistence occurs following treatment with these adjuvant modalities. Intralesional cidofovir may help control papilloma regrowth and reduce disease severity in many children with RRP [39]. In most cases, cidofovir would appear to be less efficacious in producing disease eradication. There appears to be little evidence to support prolonged treatment regimes (i.e. more than eight treatments) [35]. Subcutaneously injected cidofovir has been tested on cartilage in a rabbit model [39]. There was a positive doseresponse relationship which existed for gross skin changes; however, there was no dose-response relationship for severity of change in the epithelium. Higher doses of cidofovir than commonly are used in the treatment of RRP may be safe, although the effects of repeat application and longterm complications are not yet known. In animals, cidofovir is carcinogenic (mammary adenocarcinoma in rats), embryotoxic and teratogenic [48]. Care must be taken in humans that the possibility of pregnancy is excluded when usage is considered. In view of the severe nephrotoxicity shown when intravenous cidofovir is administered to animals and humans, caution would be advised for repeated intralesional or subcutaneous applications for RRP treatment. The less common complications of bone marrow toxicity, iritis and uveitis may also arise and vigilance is required from clinicians.

Controlled trials failed to provide sufficient evidence to draw reliable conclusions about the effectiveness of antiviral agents as adjuvant therapy in the management of RRP. Further research is required before any specific antiviral adjuvant therapy can be recommended.

Factors leading to virus activation in RRP have not been recognized, however, extra-oesophageal acid reflux disease (EERD) has been suggested as a possible factor, initially by Borkowski et al. [6], and then by a group from Harvard in 2005 [29]. There is clinical evidence suggesting a link between the presence of EERD and RRP. Inflammation induced by acid exposure may result in the expression of HPV in susceptible tissues. Therefore, treatment of EERD should be considered in all patients with difficult to control RRP with EERD.

Despite currently available surgical and adjuvant management options, tracheotomy may become necessary in selected patients with extensive disease. Decannulation should be performed as early as possible to avoid further spread of viral infection and improve the quality of life. The primary cause of papilloma extension to the lower airways appears to be iatrogenic, i.e. the tracheotomies performed in children with laryngeal papillomatosis $(92.5 \%$ of 
cases). This was reported in a case group of 448 children with RRP treated in St. Vladimir Moscow Children's Hospital between 1988 and 2003 [38].

The recent licensing of prophylactic HPV vaccines is a most interesting development. In particular, the quadrivalent vaccine from Merck \& Sanofi-Pasteur $\left(\right.$ Gardasil ${ }^{\circledR}$ ) which shows efficacy against HPV 6, 11, 16, 18 subtypes, may be anticipated to impact upon the incidence of RRP. The low incidence of RRP does pose significant problems in recruitment of sufficient numbers to show statistical significance. Large multi-centre collaborative clinical trials are therefore required. Even so, sufficient clinical follow-up data would take several years.

\section{References}

1. Armstrong LR, Derkay CS, Reeves WC (1999) Initial results from the national registry for juvenile-onset recurrent respiratory papillomatosis. RRP Task Force. Arch Otolaryngol Head Neck Surg 125:743-748

2. Barbosa MS, Vass WC, Lowy DR, Schiller JT (1991) In vitro biological activities of the E6 and E7 genes vary among human papillomaviruses of different oncogenic potential. J Virol 65:292-298

3. Bedell MA, Hudson JB, Golub TR, Turyk ME, Hosken M, Wilbanks GD, Laimins LA (1991) Amplification of human papillomavirus genomes in vitro is dependent on epithelial differentiation. $\mathrm{J}$ Virol 65:2254-2260

4. Bomholt A (1988) Juvenile laryngeal papillomatosis. An epidemiological study from the Copenhagen region. Acta Otolaryngol 105:367-371

5. Bomholt A (1988) Laryngeal papillomas with adult onset. An epidemiological study from the Copenhagen region. Acta Otolaryngol 106:140-144

6. Borkowski G, Sommer P, Stark T, Sudhoff H, Luckhaupt H (1999) Recurrent respiratory papillomatosis associated with gastroesophageal reflux disease in children. Eur Arch Otorhinolaryngol 256:370-372

7. Bosch FX, Manos MM, Munoz N, Sherman M, Jansen AM, Peto J, Schiffman MH, Moreno V, Kurman R, Shah KV (1995) Prevalence of human papillomavirus in cervical cancer: a worldwide perspective. International biological study on cervical cancer (IBSCC) Study Group. J Natl Cancer Inst 87:796-802

8. De Geest K, Turyk ME, Hosken MI, Hudson JB, Laimins LA, Wilbanks GD (1993) Growth and differentiation of human papillomavirus type $31 \mathrm{~b}$ positive human cervical cell lines. Gynecol Oncol 49:303-310

9. Derkay CS (1995) Task force on recurrent respiratory papillomas. A preliminary report. Arch Otolaryngol Head Neck Surg 121:1386-1391

10. Dickens P, Srivastava G, Loke SL, Larkin S (1991) Human papillomavirus 6, 11, and 16 in laryngeal papillomas. J Pathol 165:243-246

11. Evander M, Frazer IH, Payne E, Qi YM, Hengst K, McMillan NA (1997) Identification of the alpha6 integrin as a candidate receptor for papillomaviruses. J Virol 71:2449-2456

12. Flores ER, Allen-Hoffmann BL, Lee D, Sattler CA, Lambert PF (1999) Establishment of the human papillomavirus type 16 (HPV16) life cycle in an immortalized human foreskin keratinocyte cell line. Virology 262:344-354

13. Hallden C, Majmudar B (1986) The relationship between juvenile laryngeal papillomatosis and maternal condylomata acuminata. J Reprod Med 31:804-807
14. Heck DV, Yee CL, Howley PM, Munger K (1992) Efficiency of binding the retinoblastoma protein correlates with the transforming capacity of the E7 oncoproteins of the human papillomaviruses. Proc Natl Acad Sci USA 89:4442-4446

15. Herrero R, Castellsague X, Pawlita M, Lissowska J, Kee F, Balaram P, Rajkumar T, Sridhar H, Rose B, Pintos J, Fernandez L, Idris A, Sanchez MJ, Nieto A, Talamini R, Tavani A, Bosch FX, Reidel U, Snijders PJ, Meijer CJ, Viscidi R, Munoz N, Franceschi S (2003) Human papillomavirus and oral cancer: the international agency for research on cancer multicenter study. J Natl Cancer Inst 95:1772-1783

16. HPA (2006) Trends in anogenital warts and anogenital herpes simplex virus infection in the United Kingdom: 1996 to 2005. CDR Wkly $16: 1-4$

17. IARC (2005) IARC Monographs on the evaluation of carcinogenic risks to humans. IARC Monographs vol 90, Lyon, France.Working group on HPV 15-22 February 2005. (http:// monographs,iarc,fr/ENG/Meetings/90-hpv.pdf)

18. Joyce JG, Tung JS, Przysiecki CT, Cook JC, Lehman ED, Sands JA, Jansen KU, Keller PM (1999) The L1 major capsid protein of human papillomavirus type 11 recombinant virus-like particles interacts with heparin and cell-surface glycosaminoglycans on human keratinocytes. J Biol Chem 274:5810-5822

19. Kashima H, Mounts P, Leventhal B, Hruban RH (1993) Sites of predilection in recurrent respiratory papillomatosis. Ann Otol Rhinol Laryngol 102:580-583

20. Kashima HK, Shah F, Lyles A, Glackin R, Muhammad N, Turner L, Van Zandt S, Whitt S, Shah K (1992) A comparison of risk factors in juvenile-onset and adult-onset recurrent respiratory papillomatosis. Laryngoscope 102:9-13

21. Kjer JJ, Eldon K, Dreisler A (1988) Maternal condylomata and juvenile laryngeal papillomas in their children. Zentralbl Gynakol 110:107-110

22. Koutsky LA, Galloway DA, Holmes KK (1988) Epidemiology of genital human papillomavirus infection. Epidemiol Rev 10:122-163

23. Kreimer AR, Clifford GM, Boyle P, Franceschi S (2005) Human papillomavirus types in head and neck squamous cell carcinomas worldwide: a systematic review. Cancer Epidemiol Biomarkers Prev 14:467-475

24. Lechner MS, Laimins LA (1994) Inhibition of p53 DNA binding by human papillomavirus E6 proteins. J Virol 68:4262-4273

25. Lindeberg H, Elbrond O (1990) Laryngeal papillomas: the epidemiology in a Danish subpopulation 1965-1984. Clin Otolaryngol Allied Sci 15:125-131

26. Lindeberg H, Johansen L (1990) The presence of human papillomavirus (HPV) in solitary adult laryngeal papillomas demonstrated by in-situ DNA hybridization with sulphonated probes. Clin Otolaryngol Allied Sci 15:367-371

27. McIntyre MC, Frattini MG, Grossman SR, Laimins LA (1993) Human papillomavirus type 18 E7 protein requires intact Cys-X$\mathrm{X}$-Cys motifs for zinc binding, dimerization, and transformation but not for Rb binding. J Virol 67:3142-3150

28. McKaig RG, Baric RS, Olshan AF (1998) Human papillomavirus and head and neck cancer: epidemiology and molecular biology. Head Neck 20:250-265

29. McKenna M, Brodsky L (2005) Extraesophageal acid reflux and recurrent respiratory papilloma in children. Int J Pediatr Otorhinolaryngol 69:597-605

30. McMillan NA, Payne E, Frazer IH, Evander M (1999) Expression of the alpha6 integrin confers papillomavirus binding upon receptor-negative B-cells. Virology 261:271-279

31. Oh ST, Longworth MS, Laimins LA (2004) Roles of the E6 and E7 proteins in the life cycle of low-risk human papillomavirus type 11. J Virol 78:2620-2626

32. Rady PL, Schnadig VJ, Weiss RL, Hughes TK, Tyring SK (1998) Malignant transformation of recurrent respiratory papillomatosis 
associated with integrated human papillomavirus type 11 DNA and mutation of p53. Laryngoscope 108:735-740

33. Schlegel R, Phelps WC, Zhang YL, Barbosa M (1988) Quantitative keratinocyte assay detects two biological activities of human papillomavirus DNA and identifies viral types associated with cervical carcinoma. EMBO J 7:3181-3187

34. Shah K, Kashima H, Polk BF, Shah F, Abbey H, Abramson A (1986) Rarity of cesarean delivery in cases of juvenile-onset respiratory papillomatosis. Obstet Gynecol 68:795-799

35. Sheahan P, Sexton S, Russell JD (2006) Is intralesional cidofovir worthwhile in juvenile recurrent respiratory papillomatosis? J Laryngol Otol 120:561-565

36. Sherman L, Jackman A, Itzhaki H, Stoppler MC, Koval D, Schlegel R (1997) Inhibition of serum- and calcium-induced differentiation of human keratinocytes by HPV16 E6 oncoprotein: role of p53 inactivation. Virology 237:296-306

37. Silverberg MJ, Thorsen P, Lindeberg H, Grant LA, Shah KV (2003) Condyloma in pregnancy is strongly predictive of juvenileonset recurrent respiratory papillomatosis. Obstet Gynecol 101:645-652

38. Soldatski IL, Onufrieva EK, Steklov AM, Schepin NV (2005) Tracheal, bronchial, and pulmonary papillomatosis in children. Laryngoscope 115:1848-1854

39. Spiegel JH, Andrus JG, Stefanato CM, Heeren T (2005) Histopathologic effects of cidofovir on cartilage. Otolaryngol Head Neck Surg 133:666-671

40. Stamataki S, Nikolopoulos TP, Korres S, Felekis D, Tzangaroulakis A, Ferekidis E (2007) Juvenile recurrent respiratory papillomatosis: still a mystery disease with difficult management. Head Neck 29:155-162

41. Stanley MA, Browne HM, Appleby M, Minson AC (1989) Properties of a non-tumorigenic human cervical keratinocyte cell line. Int J Cancer 43:672-676
42. Storey A, Pim D, Murray A, Osborn K, Banks L, Crawford L (1988) Comparison of the in vitro transforming activities of human papillomavirus types. EMBO J 7:1815-1820

43. Strong MS, Vaughan CW, Cooperband SR, Healy GB, Clemente MA (1976) Recurrent respiratory papillomatosis: management with the CO2 laser. Ann Otol Rhinol Laryngol 85:508-516

44. Tasca RA, McCormick M, Clarke RW (2006) British association of paediatric Otorhinolaryngology members experience with recurrent respiratory papillomatosis. Int J Pediatr Otorhinolaryngol 70:1183-1187

45. Walboomers JM, Jacobs MV, Manos MM, Bosch FX, Kummer JA, Shah KV, Snijders PJ, Peto J, Meijer CJ, Munoz N (1999) Human papillomavirus is a necessary cause of invasive cervical cancer worldwide. J Pathol 189:12-19

46. Werness BA, Levine AJ, Howley PM (1990) Association of human papillomavirus types 16 and 18 E6 proteins with p53. Science 248:76-79

47. Wiatrak BJ, Wiatrak DW, Broker TR, Lewis L (2004) Recurrent respiratory papillomatosis: a longitudinal study comparing severity associated with human papilloma viral types 6 and 11 and other risk factors in a large pediatric population. Laryngoscope 114:123

48. Wutzler P, Thust R (2001) Genetic risks of antiviral nucleoside analogues-a survey. Antiviral Res 49:55-74

49. Zeitels SM, Akst LM, Burns JA, Hillman RE, Broadhurst MS, Anderson RR (2006) Office-based 532-nm pulsed KTP laser treatment of glottal papillomatosis and dysplasia. Ann Otol Rhinol Laryngol 115:679-685

50. Zhang P, Nouri M, Brandsma JL, Iftner T, Steinberg BM (1999) Induction of E6/E7 expression in cottontail rabbit papillomavirus latency following UV activation. Virology 263:388-394 